\title{
Effects of Methadone Exposure during Development on Avian Brain and Blood Cells
}

\author{
Zofia Gagnon*, Sherry Dingman, Christina D’Arco, Megann McGinnis \\ Marist College; Poughkeepsie, NY, USA \\ Email: 'Zofia.Gagnon@marist.edu
}

Received 26 August 2015; accepted 26 October 2015; published 30 October 2015

Copyright (C) 2015 by authors and Scientific Research Publishing Inc.

This work is licensed under the Creative Commons Attribution International License (CC BY). http://creativecommons.org/licenses/by/4.0/

(c) (i) Open Access

\begin{abstract}
Maintenance with methadone is standard treatment for opioid-addicted patients, including pregnant women. Cellular effects of methadone exposure during development are investigated by using an avian model, which is free of confounding maternal variables. In the first study, which explored dose by duration interactions, methadone was administered at one of two doses $\mathbf{0 . 4 5 8}$ $\mathrm{mg} / \mathrm{kg}$ or $1.75 \mathrm{mg} / \mathrm{kg}$ ) for one of three durations of exposure: late in development (Incubation Days 12 to 19), middle to late (Days 9 to 19), or early to late (Days 5 to 19). In the second study, $1.00 \mathrm{mg} / \mathrm{kg}$ of methadone was administered from days 8 to 18 and compared with controls $(0.00$ $\mathrm{mg} / \mathrm{kg}$ ). Brain tissue and blood samples were harvested for all dose conditions from the two studies. Increased methadone exposure was associated with subependymal anomalies, subependymal hemorrhaging, edema, monocytic infiltration, an increase in disintegrating red blood cells, an increase in white blood cells, and a decrease in neurons. Significant differences in variance for cell counts by condition were observed. Exposed specimens had significantly more thrombocytes $(t=$ $-2.66, p<0.05)$. The anomalies suggest that methadone exposure may be harmful to develop organisms at the cellular level.
\end{abstract}

\section{Keywords}

Methadone, Embryonic Development, Chicks, Neuropathology, Hematology, Opioids

\section{Introduction}

Maintenance therapy with methadone is now standard practice for treating pregnant heroin users. In theory, maintenance improves psychosocial circumstances for mothers and increases medical compliance among pregnant patients [1]; but, in fact, many at-risk women abuse medical opioids during pregnancy [2]. Substitution

\footnotetext{
${ }^{*}$ Corresponding author.
} 
therapy frequently leads to the newborn suffering through neonatal abstinence syndrome [3]. In developing rats, myelination is altered by perinatal exposure to therapeutic doses of methadone [4].

Methadone persists in the liver where it is metabolized [5]. It binds to gut, kidney, liver, muscle, and lung tissue, and is highly bound to plasma proteins [6] [7]. In the brain, methadone is a pure mu-opioid agonist without significant kappa or delta receptor activity [8]. It also has an affinity for the N-methyl-D-aspartate (NMDA) inotropic glutamate receptors where endogenous enkephalins and beta endorphins bind. Mu-opioid receptors mediate changes in neural transmission by way of inhibition of presynaptic release of GABA [9]. The analgesic properties of methadone are due to its structural similarity to endogenous enkephalins and endorphins. Its addictive properties are thought to be produced indirectly by suppressing the release of GABA, which normally inhibits the release of dopamine [10]. Like other drugs of abuse, opioids lead to release of dopamine in the nucleus accumbens.

Various immune system cells express opioid receptors and undergo apoptosis when treated with opioid alkaloids, and mounting evidence suggests opioids may affect neuronal survival as well [11]. Drugs are capable of producing immune hemolytic anemia through the production of antibodies that react with red blood cells in the presence of the drug or its metabolites, leading to intravascular hemolysis. Even in the absence of the drug itself, antibodies may lead to extravascular hemolysis [12].

Outcomes for children prenatally exposed to methadone are commonly attributed to postnatal environmental and/or maternal factors [13] [14]. The web site Methadone and Pregnancy assures readers, "Pregnant women have been treated with methadone for more than 25 years and neither methadone nor other opiates have ... been shown to directly cause birth defects. However, your baby may experience some side effects from methadone. The most common are smaller-than-normal head size, low birth weight, and withdrawal symptoms” [15]. Contrary to the reassuring claim on this web page, there is evidence of elevated congenital malformations in children prenatally exposed to therapeutic opioids [16]. The Center for Disease Control warns that opioid users, including those on methadone, are twice as likely to have infants with neural tube defects [17].

In animal studies there has been evidence of adverse effects from opioid exposure since an early study reported a four- to six-fold increase in congenital malformation of the nervous system from repetitive doses of methadone in hamsters, an effect that could be blocked by opiate antagonists [18]. More recently, neurobehavioral teratogenicity was reported in mice whose mothers were injected on gestation days 9 - 18 with $10 \mathrm{mg} / \mathrm{kg}$ of heroin, with the deficits proving reversible when neural progenitor cells were grafted to the hippocampus, with most of the progenitor cells becoming astrocytes [19].

As part of an ongoing project investigating direct effects of methadone and heroin on development by using an avian model free of confounding maternal variables, we investigated some of the cellular consequences of exposure to methadone. We examined brain tissue from the avian "prefrontal" cortex [20] and blood cells (leukocytes, thrombocytes, and erythrocytes).

\section{Methods}

Experimental Model. The chick embryo (Gallus gallus domesticus) is a well accepted research model in developmental biology, genetics, immunology, embryology, pharmacology, and toxicology [21]. The Office for Protection from Research Risks (OPRR) does not consider in ova chicks to be vertebrates prior to hatching, making them ideal specimens for teaching institutions [22].

Specific pathogen-free eggs were obtained from Charles River Laboratories, Inc. (North Franklin, CT). Eggs for both experiments were prepared using the procedure followed by Gagnon et al. [23]. Upon arrival, eggs were prepared for injection. A rotary drill was used to create $1 \mathrm{~mm}$ holes perforating only the exterior shell layer above the air sac, leaving the internal membrane intact. The holes were sealed with clear tape. Eggs were randomly assigned to conditions and distributed throughout a forced-air incubator chamber (G.Q.F. Mfg. Co., Model 1502) at $38^{\circ} \mathrm{C} \pm 1{ }^{\circ} \mathrm{C}$. Constant humidity in the range $50 \%-55 \%$ was maintained using a drip pan filled with sterile water. The incubator's automatic turner changed egg position every four hours to ensure equal environmental conditions and simulating the natural nesting condition of hens.

Experimental Design. The first experiment was designed to investigate the interaction of dose by duration of exposure. Women may seek methadone treatment at any time during pregnancy, and then typically continue treatment until delivery or beyond. $\mathrm{N}=42$ eggs were used $(\mathrm{N}=6$ eggs in each of six conditions and $\mathrm{N}=6$ controls). Three exposure periods for daily injections were selected for this study based upon stages of chick devel- 
opment [24] roughly comparable to stages of interest in human development (Table 1). It is known that opiate analgesics during the first trimester are linked to birth defects [16]. Therefore, since the chick embryo has its organs by the end of day four we delayed starting methadone treatments until day five. An additional reason for instituting the early to late exposure period as days 5 to 19 is that somites are well established by day 5 . Incubation Day 12 corresponds to approximately 60 percent of the way through gestation. Establishing the late exposure condition as incubation days 12 through 19 would be roughly equivalent to a woman being in methadone maintenance during her last trimester. Beginning on day 12 also allows consideration of effects just prior to completion of structural differentiation on day 14. Day 9 is about half way between day 5 and day 12; and the period before Day 9 is critical, with many dynamic changes in the wings, legs, and visceral arches [24]-[26]. Thus days 9 through 19 were selected as the middle exposure period.

Doses were calculated based on those given to pregnant women as reported in published studies of longitudinal outcomes for exposed infants. In early studies, doses were typically 20 - $40 \mathrm{mg}$ per day. Now much higher doses may be administered, up to $160 \mathrm{mg}$ a day, to prevent relapse [27] [28]. Making an assumption about the approximate weight of a typical pregnant woman and a typical weight of $20 \mathrm{~g}$ for a chick on Incubation Day 18, the low dose (LD) for our study was calculated to be $\mathrm{mg} / \mathrm{kg} 0.458$ and the high dose (HD) as $1.75 \mathrm{mg} / \mathrm{kg}$. The six treatment conditions consisted of: LD/early to late period, HD/early to late period, LD/middle to late period, $\mathrm{HD} /$ middle to late period, LD/late period, and HD/late period. Each of the 6 controls received sham injections (without methadone) from days 5 to 19.

Because eggs are a closed system, drug doses had to be administered in a very small amount of vehicle. Methadone, at the dose specified for the condition, was administered in a vehicle of $10 \mu \mathrm{l}$ phosphate buffered saline (PBS) solution (NERL ${ }^{\circledR}$ Blood Bank Saline, Fisher Diagnostics) directly into the air sac using a 0.5 cc insulin syringe (Fisher Scientific). Control eggs received injections containing $10 \mu \mathrm{l}$ of vehicle only. Injections were administered every $24 \mathrm{hrs} \pm 1 \mathrm{hr}$. The internal embryonic membrane was not perforated, and the drug solution was allowed to slowly diffuse across the membrane into the embryo's circulatory system.

In the second experiment, $\mathrm{N}=36$ eggs ( $\mathrm{N}=18$ exposed and $\mathrm{N}=18$ controls) were dosed with $1.00 \mathrm{mg} / \mathrm{kg}$ of methadone (Table 2). This amount, chosen because it is approximately half way between the first study's doses, is referred to as the medium dose (MD). The lone exposure period for the second study ran from day 8 to day 18 . Because so many of the early to late period exposed eggs in the first experiment died during development, the injection period was scheduled to not begin until day 8 . The eggs in the second study were part of a larger experiment investigating growth trajectory over development. Methadone in that study was administered only until day 18 so investigators could observe chicks for signs of withdrawal [29]. Other than exposure period, methadone dose and group size, all preparations and conditions for the second experiment were identical to the first. Injections were prepared and administered as in the first experiment; and drug doses, as described above, were calculated in the same fashion. Ten exposed and ten control specimens were selected randomly for collection of blood and tissue samples.

In both experiments, eggs were opened on Incubation Day 20, chicks were sacrificed by cervical decapitation, and tissues and blood were harvested. Tissue samples were taken from regions of the chicken brain shown to have high levels of mu-opioid receptors, including the mesopallium (formerly called the hyperstriatum) and the nidopallium (formerly called the neostriatum) [30].

Table 1. Illustrating the experimental design of study one.

\begin{tabular}{cccc}
\hline Treatment & Day 5 to 19 & Day 9 to 19 & Day 12 to 19 \\
\hline Low dose $0.458 \mathrm{mg} / \mathrm{kg}$ & $\mathrm{N}=6$ & $\mathrm{~N}=6$ & $\mathrm{~N}=6$ \\
High Dose $1.75 \mathrm{mg} / \mathrm{kg}$ & $\mathrm{N}=6$ & $\mathrm{~N}=6$ & $\mathrm{~N}=6$ \\
Vehicle only & & & $\mathrm{N}=6$ \\
\hline
\end{tabular}

Table 2. Illustrating the experimental design of study two.

\begin{tabular}{cc}
\hline Treatment & Duration of Exposure Days 8 to 18 \\
\hline Medium Dose $1.00 \mathrm{mg} / \mathrm{kg}$ & $\mathrm{N}=18$ \\
Controls $0.00 / \mathrm{mg} / \mathrm{kg}$ & $\mathrm{N}=18$ \\
\hline
\end{tabular}


Hematological Analysis. Blood for analysis was extracted via heart puncture using a hypodermic syringe (Fisher Scientific). One drop of blood was placed onto a microscope slide that had been pre-cleaned with alcohol and allowed to air dry. A wedge smear was made using a spreader slide. Two or three blood smears were created per specimen depending on the volume of blood collected. The slides were stained with Wright Giemsa Stain (Diff-Quik Stain). Using a bright field microscope (Olympus BX51, Olympus UPlanAPO $100 \times 1.35$ Oil Iris) with oil immersion objective (1000× magnification), the number of thrombocytes, white blood cells, and disintegrating erythrocytes were recorded out of 1000 blood cells for each of the smears collected. Cell counts for all slides per specimen were averaged together to build a data file with one record per specimen.

Histological Analysis. Chick brain tissue was harvested, cut into sagittal sections, and stored in 10\% phosphate buffered formalin (Fisher Scientific). Slides were prepared and analyzed at Pathology Corporation of America Laboratories in Wrightstown, NJ. Fixed tissues were embedded in paraffin (Richard-Allan Scientific) and cut into 3 - $5 \mu \mathrm{m}$ thick sections using an Olympus CUT 4060 precision microtome (Center Valley, PA) for analysis. Hematoxylin and Eosin (H\&E) stain was used to visualize neuronal nuclei, neuropil, and vascular structures. Gomori Methenamine Stain (GMS) was used to highlight the difference between cell body and neuropil. Reticulin stain (a modified silver stain) was used to highlight neuropil. Periodic-acid Schiff stain, (PAS) was used to visualize mucin, a substance that may be produced by neuropil breakdown. Finally, a monoclonal leukocyte common antigen (LCA) was used to highlight inflammatory cells.

From prepared slides, the area of the subependymal zone was measured using Olympus cellSens Digital Imaging Software. Only the area consisting of the cluster of packed cells in the subependymal layer of the lateral ventricle (equivalent to the germinal matrix (GM) in human brain) was measured $\left(\mu \mathrm{m}^{2}\right)$, indicated by arrows on Figures 1(a)-(d). Point-to-point measurements were manually taken of each slide at $200 \times$ magnification using

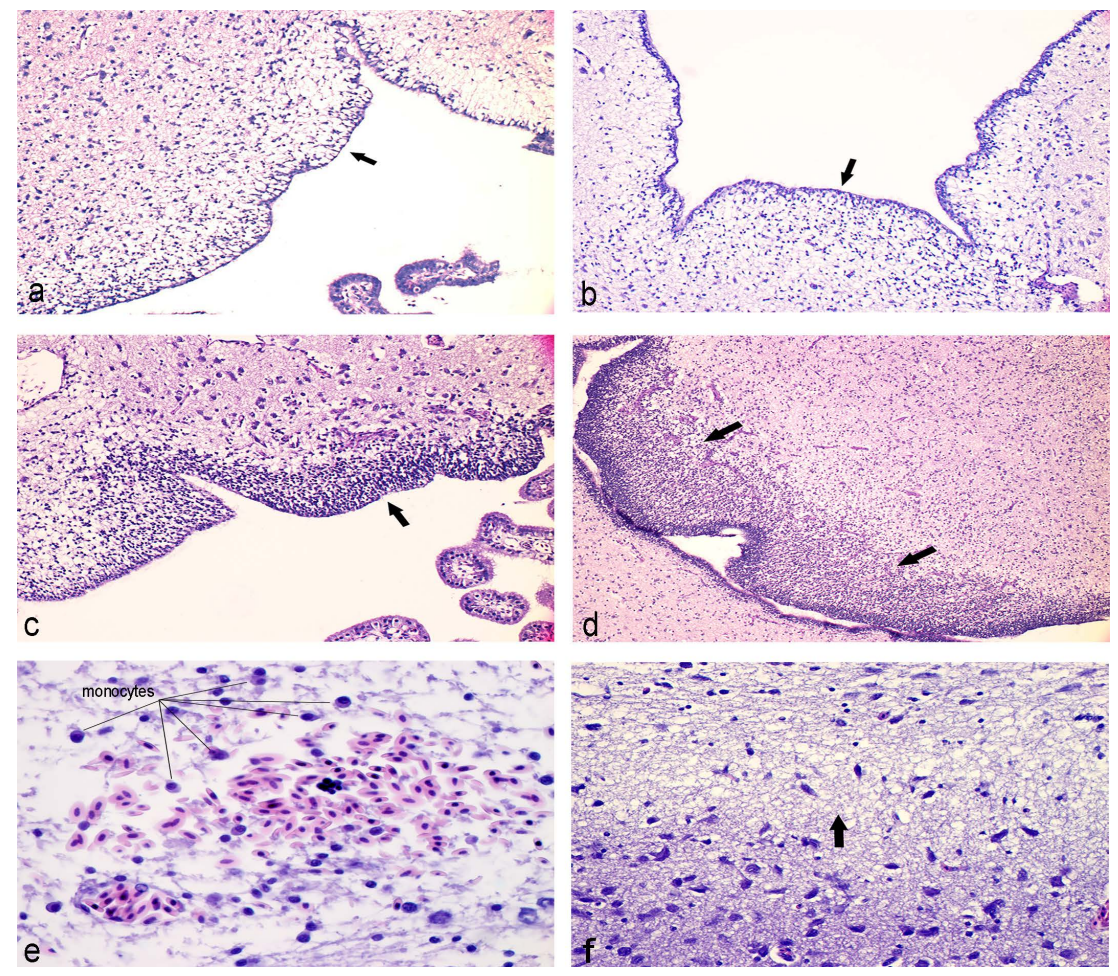

Figure 1. (a) Control section stained with H\&E of the lateral ventricle wall show regions where a normal subependymal layer (arrow) is present (400×); (b) Subependymal layer along lateral ventricle wall (arrow) of a characteristic low-dose specimen has thickened slightly but does not show a considerable change from the control (H\&E, 400×); (c) Characteristic medium dose specimen exhibits more prominent progenitor glial cell proliferation (arrow) along lateral ventricle wall compared to (a) and (b) (H\&E, 400×); (d) Subependymal progenitor glial cell population (arrows) seen in a characteristic high dose specimen has intensified greatly from (a), (b) and (c) (H\&E, 400×); (e) Blood cells ruptured from nearby vessels indicate area of hemorrhaging in subependymal-ventricular zone accompanied by monocyte infiltration in a high dose specimen (H\&E, 1000×); (f) Possible edema (direction of arrow) located in the subependymal-ventricular zone near area of hemorrhaging in same specimen as in (e) (H\&E, 1000×). 
the surface area tool. Quantification of the number of neuronal cells and vascular structures in the area measured was performed at $400 \times$ magnification. A randomized permanent ink dot was placed on the slide. The field of view was placed over the dot, and counting was done in a horizontal fashion from right to left for the cells in the field of view. Ten high power fields were counted in this way. The results were recorded (total 31 slides) and averaged for each specimen, and treatment groups were compared.

Statistical Analysis. The SPSS statistical package (ver. 16.0, IBM, Armonk, NY, USA) was used to analyze hematology and the subependymal area. Statistical difference between number of leucocytes, thrombocytes and disintegrating blood cells in different treatments was detected via One-Way ANOVA $(p \leq 0.05)$ and determined by post hoc Student-Neuman-Keuls multiple comparison tests at the probability level $\alpha \leq 0.05$. Microsoft's Excel program and SPSS were used for statistical analysis and preparation of stem plots of blood cells counts in different treatment groups.

\section{Results}

Because of the unequal numbers of surviving embryos by duration of exposure conditions in the first study, we pooled data by dose conditions for analyses presented here $(0.485 \mathrm{mg} / \mathrm{kg}, 1.00 \mathrm{mg} / \mathrm{kg}$, and $1.75 \mathrm{mg} / \mathrm{kg})$. The results presented here therefore combine data from the two studies to report results of dose conditions.

Hematology. Hematological analysis of prepared blood smears revealed pathological changes in methadone-exposed chick embryos. Instances of erythrocytes were seen undergoing various degrees of karyorrhexis (Figure 2). The presence of monocytes and thrombocytes accompanying erythrocyte disintegration is shown in Figure 3. Observations included erythrocytes without hemoglobin, with a nucleus just beginning to disintegrate, and erythroplastids (denucleated shells).

The mean $(M)$ number of leukocytes increased in the treatment groups, as compared to each group's respective controls, but not significantly (Figure 4); and there was no significant difference between groups in mean number of leukocytes $(\mathrm{t}=11.38, \mathrm{p}=0.10)$. The variance in number of leukocytes differed significantly by conditions $(\mathrm{F}=5.3, \mathrm{p}<0.05)$. Leukocytosis, an increase in the number of white blood cells, is frequently a sign of an inflammatory response, it can occur in response to stress.

Thrombocyte numbers in control embryos from the first $(M=1.6$, S.D. $=1.4)$ and second $(M=1.8$, S.D. $=1.3)$ studies were significantly fewer than number of thrombocytes from exposed chicks (LD: $M=8.7$, S.D. = 7.7; MD: $M=7.1$, S.D. = 5.8; HD: $M=9.1$, S.D. = 10.3) (Figure 5). Analysis combining data of all exposure levels $(M=8.1$, S.D. $=5.7)$ against controls revealed the differences to be significant $(\mathrm{t}=-2.66, \mathrm{p}<0.05)$. The variance in numbers of thrombocytes by condition also differed significantly $(\mathrm{F}=11.1, \mathrm{p}<0.01)$. Thrombocytes

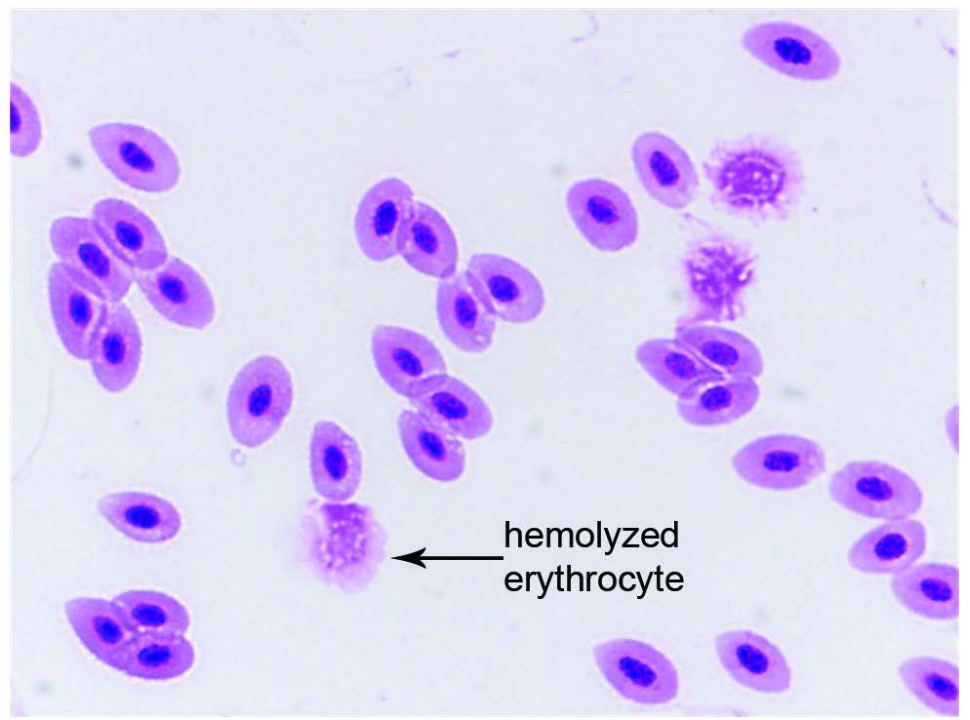

Figure 2. Healthy avian red blood cells and disintegrating (hemolyzed) red blood cells observed after treatment with medium dosage of methadone $(1000 \times)$. The disintegrating erythrocytes ranged from nucleated cells beginning to disintegrate to erythroplastids (denucleated shells). 


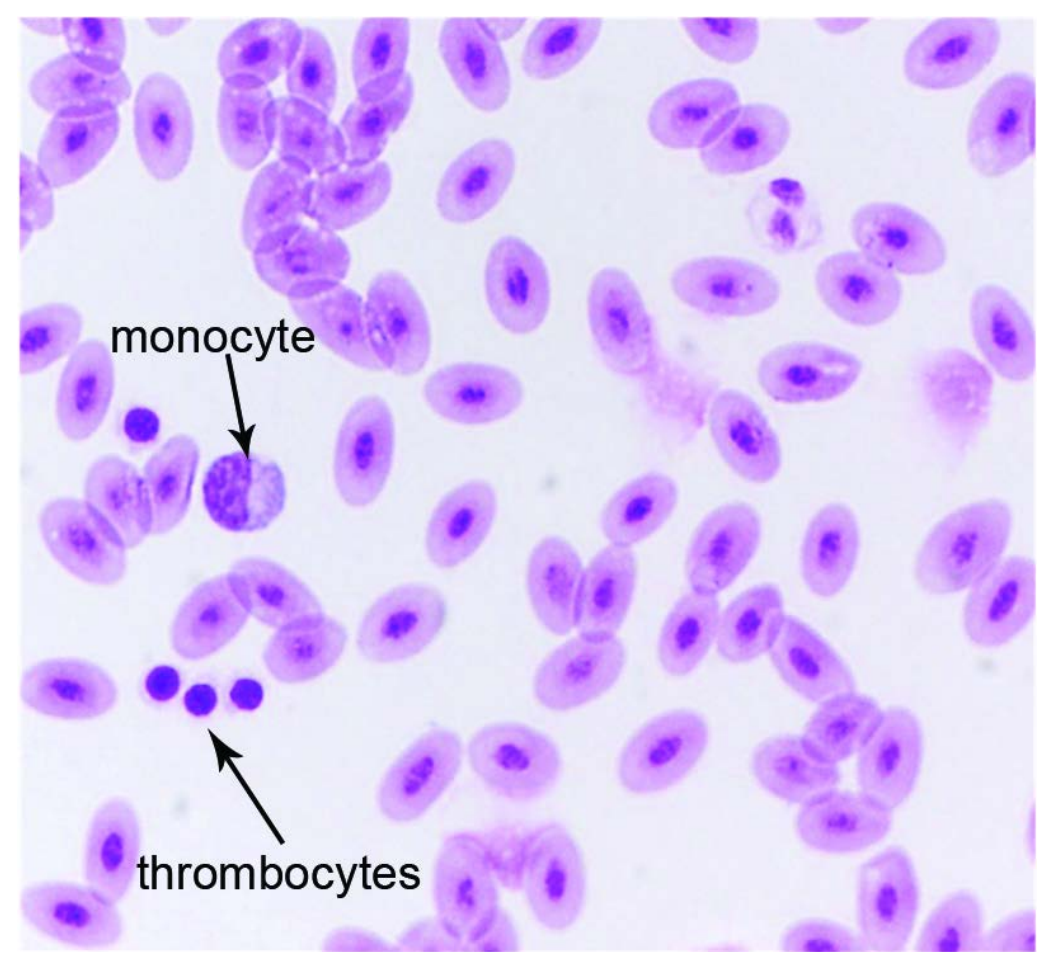

Figure 3. Healthy avian red blood cells with a mature monocyte, thrombocytes, and disintegrating blood cells after treatment with medium dosage of methadone $(1000 \times)$.

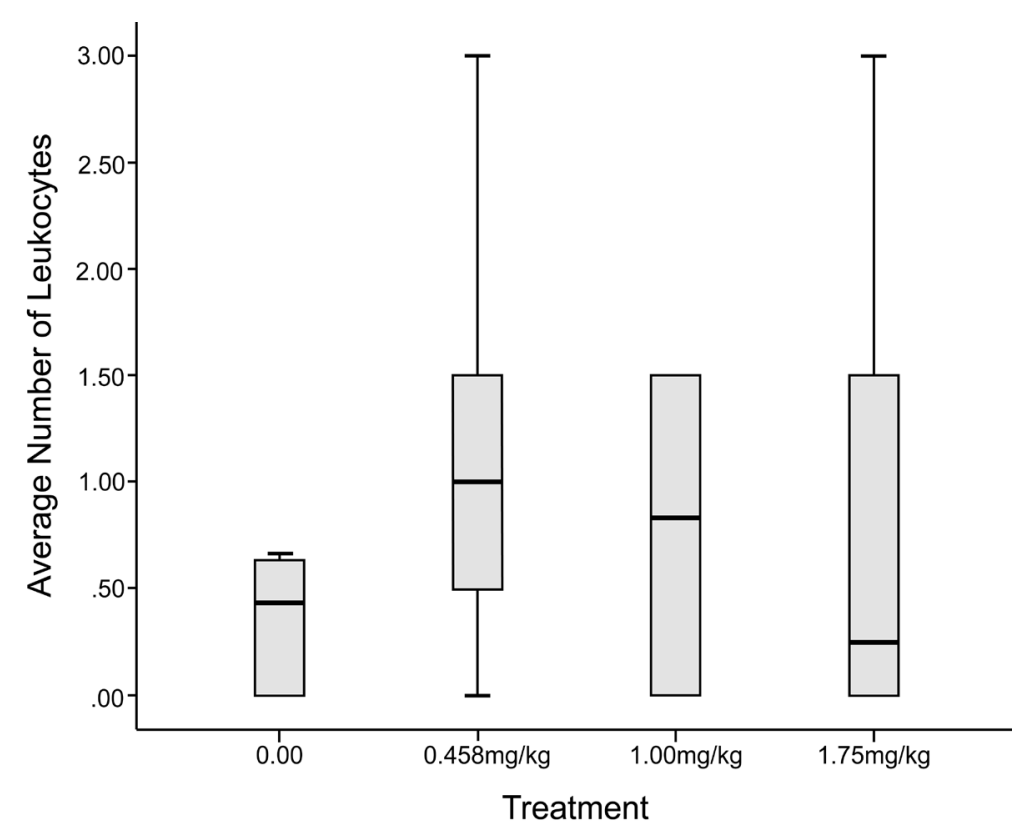

Figure 4. Leukocyte count results showed a higher number of white blood cells in methadone-treated chick embryos as compared to the control specimens. (The $1.00 \mathrm{mg} / \mathrm{kg}$ dose error bar is very short and not visible in this image).

are crucial to normal blood clotting. A possible reason for reduced numbers of these cells is small blood clots using up large numbers of them, which would be consistent with observations of gross brain bleeds observed in embryos. 


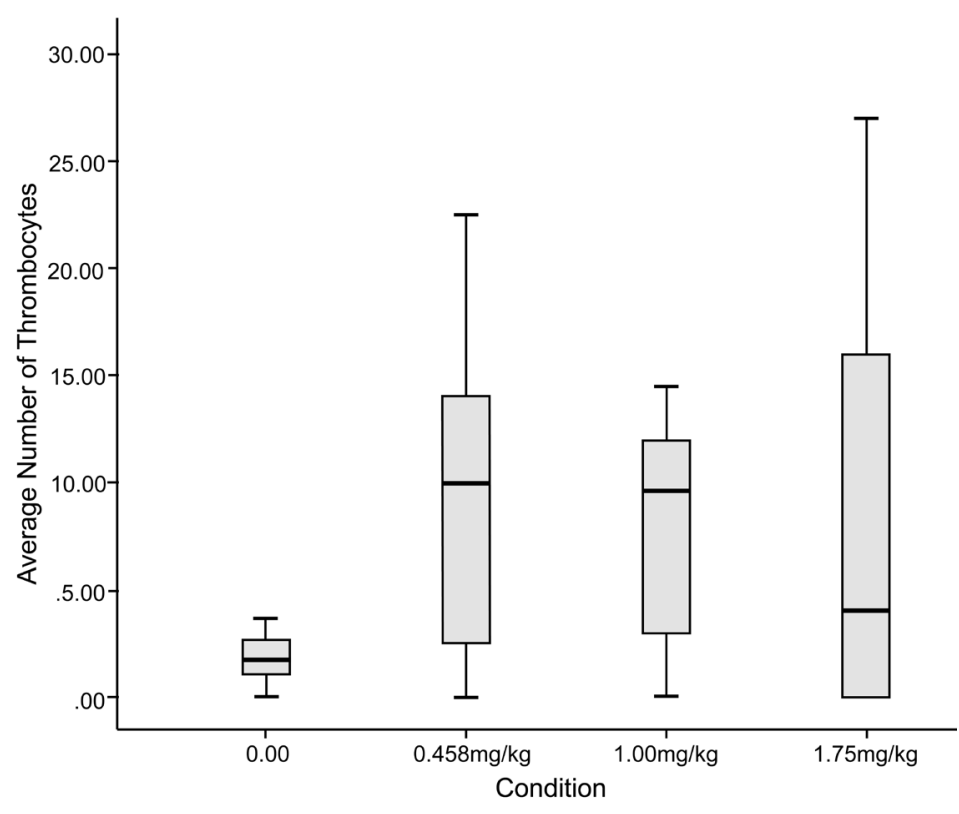

Figure 5. Thrombocyte count results showed a significantly greater number of thrombocytes in methadone-treated chick embryos as compared to control specimens.

Controls had fewer disintegrating erythrocytes $(M=24.3$, S.D. $=13.7)$ than exposed chicks $(M=34.6$, S.D. $=$ $6.6)$, $(t=-1.65, p=0.10)$, but this difference was not significant (Figure 6$)$. Variance in numbers of disintegrating erythrocytes differed significantly by condition $(\mathrm{F}=10.5, \mathrm{p}<0.01)$. Karyorrhexis is the destructive fragmentation of the nucleus of a dying cell whereby its chromatin can be seen irregularly distributed throughout the cytoplasm of the cell. It can be caused by infection, trauma or toxins. The general trend that emerged across dose conditions was for greater variability in measures of thrombocytes, white blood cells, and disintegrating erythrocytes in methadone exposed embryos by condition.

Histology. Extensive pyknotic disintegration was observed in brain tissue exposed to methadone (Figure 7). LCA staining suggested the presence of inflammatory cells (Figure 7(c)) and inconsistencies were observed for loss of structural integrity. At specimen harvest, brain hemorrhaging was observed in many of the MD and HD exposed embryos. An area of hemorrhaging in the subependymal-ventricular zone is shown in Figure 1(e) in which infiltration of monocytes in the hemorrhaging area was observed. However, several embryos from the early to late exposure group from the first experiment died early in development, so it was not possible to collect tissues from those specimens for analyses.

Histological observation revealed that the area of the subependymal zone of the lateral ventricle wall noticeably expanded in methadone-exposed brain tissue as methadone dose increased (Figures 1(a)-(d)). The average area of the subependymal zone in LD-, MD-, and HD-exposed tissue was $534.8 \mu \mathrm{m}^{2}, 2639.4 \mu \mathrm{m}^{2}$, and 7144.5 $\mu^{2}$, respectively. The average number of neurons observed in the subependymal zone of control samples was 103.4, but decreased in numbers as the methadone dose increased (Table 3). Instances of cell proliferation were also reported. Table 3 shows that the number of glial cells increased in the MD and HD treatments. Additionally, an abundance of microglial cells and clusters of undifferentiated neurons were reported in the subependymal zone of the MD and HD treatment groups.

\section{Discussion}

Methadone maintenance has been a standard treatment for pregnant heroin addicts for decades. It has long been known that infants born to mothers in methadone treatment programs are lower in birth weight, have smaller head circumference than unexposed infants, and often suffer from neonatal abstinence syndrome. In humans, these outcomes are frequently attributed to maternal factors such as poor diet, polysubstance abuse, poverty, lack of prenatal care, or high stress environments. 


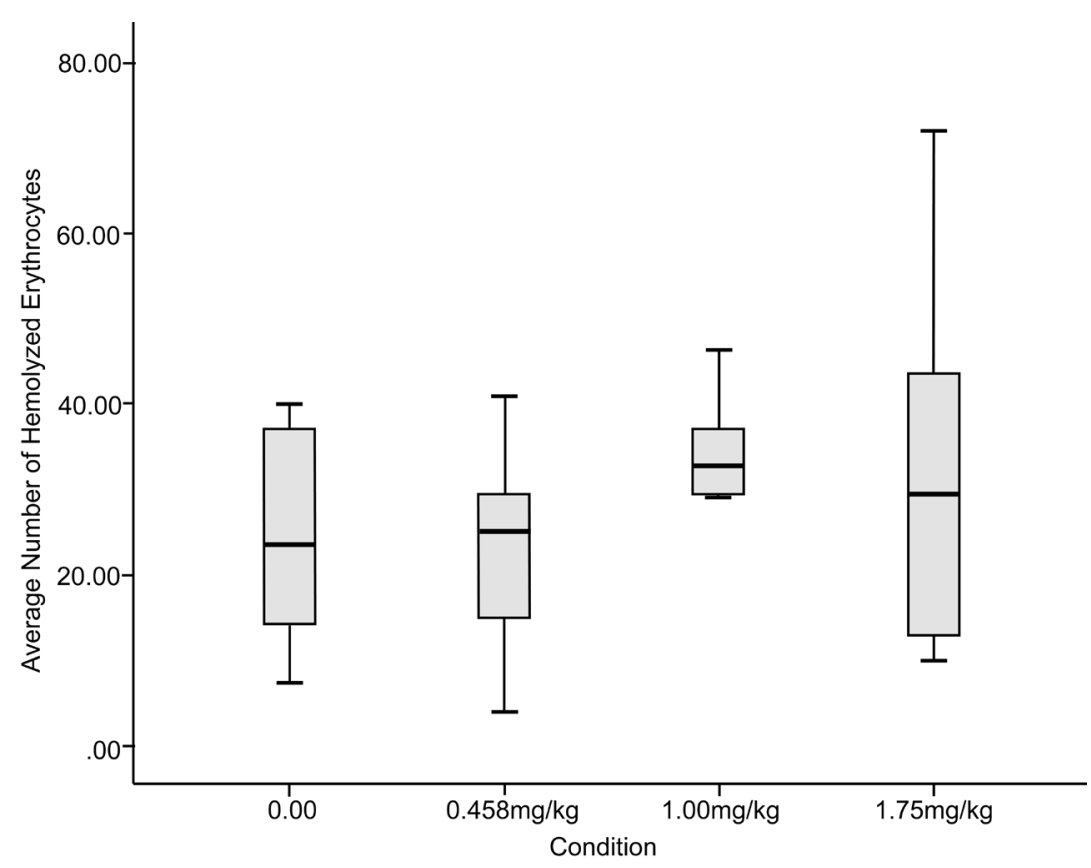

Figure 6. Disintegrating erythrocyte count results. As the dosage of methadone increased, there was a greater number of hemolyzed (denucleated) red blood cells.
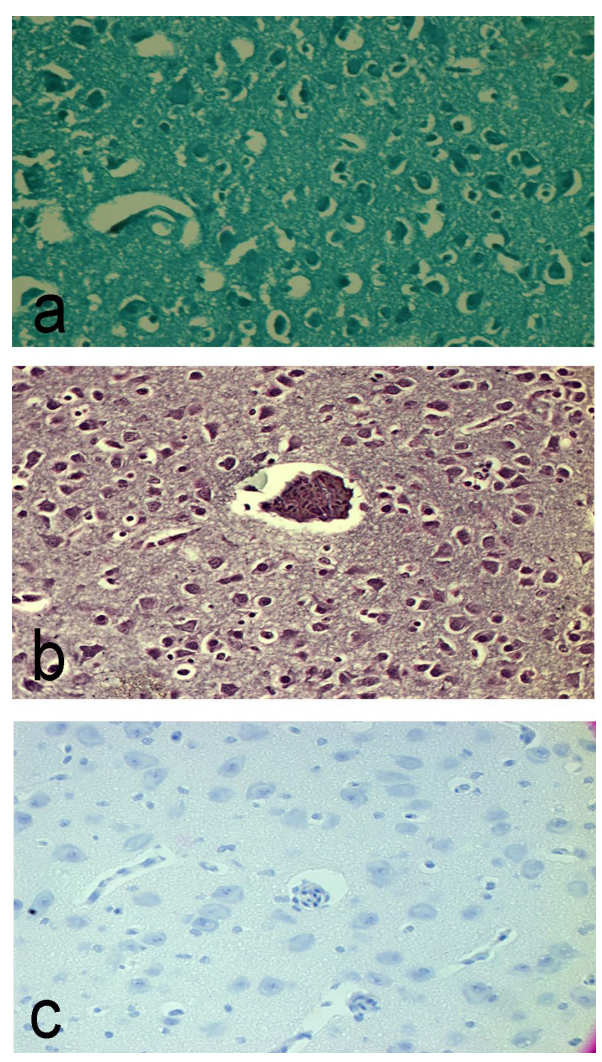

Figure 7. (a) GMS stain showing the neuropil and neurons within a frontal cerebrum cross section (HD specimen; 1000×); (b) Reticulin stain highlighting the supportive connective tissue, neuropil and neural nuclei (HD specimen; 1000×); (c) LCA stain suggesting inflammatory cells within the frontal cerebrum of medium dose specimen (1000×). 
Table 3. Number of neurons and glial cells \pm SD in different methadone exposures recorded on brain histological slides in frontal sections of chick embryos harvested on day 20 of incubation.

\begin{tabular}{ccccc}
\hline \multirow{2}{*}{$\begin{array}{c}\text { Methadone Exposure } \\
(\mathrm{mg} / \mathrm{kg})\end{array}$} & Control & 0.485 & 1.00 & 1.75 \\
\cline { 2 - 5 } & $103.4 \pm 12.9$ & $81.3 \pm 12.0$ & $14.8 \pm 6.8$ & $10.6 \pm 2.8$ \\
\hline Number of Neurons & $3.8 \pm 0.0$ & $3.8 \pm 1.8$ & $4.9 \pm 1.3$ & $7.0 \pm 2.3$ \\
\hline Number of Glial Cells & & \multicolumn{4}{c}{ Experimental Group } \\
\hline
\end{tabular}

Little is known about the direct effect of methadone on developing organisms at the cellular level. This study, through an examination of blood cells and brain tissues from chicks exposed in ova during development, suggests that methadone directly causes changes at the cellular level, changes which cannot be attributed to maternal factors. Extensive pyknotic disintegration observations in brain tissue could be the result of localized apoptosis.

The hematological analyses revealed that methadone-exposed chicks had more disintegrating (hemolyzed) red blood cells, more white blood cells, and significantly more thrombocytes. Variability across conditions observed may be due to differences in duration of exposure in some dose conditions; however, genetic variation cannot be excluded.

These findings suggest a stress response and immune system suppression [31]. Not only were there significantly more thrombocytes in methadone exposed conditions, those observed were shrunken and degenerating, which is abnormal. These types of cells are more frequently observed in blood from old specimens [32]. The thrombocytosis, as well as the presence of reactive thrombocytes, suggests that methadone treatment may cause premature maturation of thrombocytes during development.

The histological analysis of cells in the region of the brain examined for this study, the avian version of the prefrontal cortex, revealed fewer neurons in the subependymal zone of exposed groups as compared to controls, suggesting that methadone may adversely affect the rate of neurogenesis during development and/or possibly induce abnormal cell migration. In medium and high dose methadone-exposed tissue, clusters of undifferentiated cells were evident, which is consistent with findings reported by Vestal-Laborde et al. [4], and immature neurons were reported. These effects may be directly related to the smaller than average head circumference seen in human infants prenatally exposed to methadone. Morphine, another mu-opioid agonist, has been shown to promote apoptosis of fetal microglia and fetal neuronal cells in culture, but not astrocytes [33], possibly through beta-arrestin 2, a negative regulator in morphine-induced, Toll-like receptor 2 mediated apoptosis [34]. Opioids may prime neurons to undergo apoptosis by inducing TLR2 expression [35].

Of particular interest was the apparent effect that methadone exposure had on the size of the subependymal germinal layer. Increasing thickness of the subventricular zone associated with increasing methadone exposure was observed in both experiments and suggests that a stress response may be occurring; but because this effect was not expected, our investigation was not designed to unveil an understanding of this pathogenesis.

The subependymal germinal layer contains fragile blood vessels, and damage to this area could be responsible for the brain bleeds observed in many medium and high dose specimens (Figure 1(e)). In rats, a population of cells within the germinal zone of the neonatal forebrain is immunoreactive to the opioid beta-endorphin [36], a finding which implicates the endogenous opioid system in regulating tissue growth [37]. The anomalies observed within the subependymal zone of the lateral ventricular wall in the higher methadone-exposed conditions could be due to increased proliferation of progenitor cells in this zone or to focal accumulation of glial cells in response to damage.

Within the subependymal zone of the lateral ventricular wall, focal accumulation of glial cells was found to be higher in methadone exposed groups. Instances of subependymal hemorrhaging, edema, and monocytic infiltration were observed only in medium and high dose groups. The finely vacuolated appearance of the neuropil seen in Figure 1(f) could represent edema, postmortem artifact, or an area of neuropil that has become slightly depleted of cells. This effect, noted on all slides with hemorrhaging, was likely caused by the dispersion of blood following trauma. A degree of uncertainty associated with the observation of inflammation in Figure 7(c) exists because the suitability of LCA stain in birds is unknown. There is evidence of ischemic brain injuries from autopsies of heroin users [38]. Monocytes respond to stress and tissue damage, eliciting an immune response, thus the presence of these cells in the brain may be a response to injury, or it might be due to the direct 
effect of methadone on immune system cells with opioid receptors [11] [39].

The subependymal-ventricular zone of the brain, in both chicks and humans, is a significant region responsible for the early formation and migration of glial cells and neurons. The proper development of neural stem and progenitor glial cells is critically dependent on the interaction between these cells and blood vessels. Such interactions provide guidance cues for migration of these cells to their final destinations in the brain. Thus any form of injury to the ventricular zone, such as bleeding and edema, could have a substantial impact in on the development of brain cells.

Monocyte infiltration in the hemorrhaging area of the subependymal-ventricular zone of brain tissue suggests an immune response. The large macrophage cells, derived from monocytes, are activated in specific and nonspecific immune responses [40]. The number of monocytes can increase in response to opsonins (antibodies), drugs, and endotoxins [41] causing tissue oxidative damage. Activated monocytes/macrophages work to prevent injury by acting as scavengers, phagocytizing cellular debris and particulate matter.

\section{Conclusion}

The damaging effects of methadone observed in this study call for additional research on the cellular effects of opioid exposure on development. Further research is warranted to investigate the functional implications of subependymal anomalies and hemorrhaging, reduced numbers of neurons, and hemolysis during development upon administration of a therapeutic opioid. Refinements to this line of inquiry will employ more specific staining techniques for microglia, for instance, HIS-C7 monoclonal antibody, which recognizes the chick form of CD45-a specific marker for immune-derived macrophages/microglial cells in the developing and mature chick CNS. Microglia would be of particular interest as they are the first and primary immune defense in the brain and are extremely sensitive to even small pathological changes. Larger sample sizes and a greater range of doses would help establish the relationship between timing of exposure and dose effects.

\section{Acknowledgements}

We would like to thank the drug supply program at the National Institute on Drug Abuse which supplied the methadone (ref. 013274) used in these studies. Dr. Leon Isaac, MD (St. Francis Hospital, Poughkeepsie, NY) and Dr. Michael McGinnis, MD, DLM (ASCP), CHCQM, FCAP, FASCP (Pathology Corporation of America Laboratories, Wrightstown, NJ) are acknowledged for their help with slide preparation and the analysis of brain pathology. And we would especially like to acknowledge the contributions of Dr. Maria Otte to this work.

\section{References}

[1] Kandall, S.R., Doberczak, T.M., Jantunen, M. and Stein, J. (1999) The Methadone-Maintained Pregnancy. Clinics in Perinatology, 26, 173-83.

[2] Launiainen, T., Nupponen, I., Halmesmäki, E. and Ojanperä, I. (2013) Meconium Drug Testing Reveals Maternal Misuse of Medicinal Opioids among Addicted Mothers. Drug Testing and Analysis, 5, 529-533. http://dx.doi.org/10.1002/dta.1459

[3] Bell, J. and Harvey-Dodds, L. (2008) Pregnancy and Injecting Drug Use, BMJ, 336, 1303-1305. http://dx.doi.org/10.1136/bmj.39514.554375.AE

[4] Vestal-Laborde, A.A., Eschenroeder, A.C., Bigbee, J.W., Robinson, S.E. and Sato-Bigbee, C. (2014) The Opioid System and Brain Development: Effects of Methadone on the Oligodendrocyte Lineage and the Early Stages of Myelination. Developmental Neuroscience, 36, 409-421. http://dx.doi.org/10.1159/000365074

[5] Trafton, J.A. and Ramani, A. (2009) Methadone: A New Old Drug with Promises and Pitfalls. Current Pain and Headache Reports, 13, 24-30. http://dx.doi.org/10.1007/s11916-009-0006-0

[6] Garrido, M.J. and Trocóniz, I.F. (1999) Methadone: A Review of Its Pharmacokinetic/Pharmacodynamic Properties. Journal of Pharmacological and Toxicological Methods, 42, 61-66. http://dx.doi.org/10.1016/S1056-8719(00)00043-5

[7] Olsen, G.D. (1973) Methadone Binding to Human Plasma Proteins. Clinical Pharmacology \& Therapeutics, 14, 338.

[8] Brunton, L.L., Lazo, J.S. and Parker, K.L. (2006) Goodman \& Gilman’s the Pharmacological Basis of Therapeutics. 11th Edition, McGraw-Hill, New York.

[9] Johnson, S.W. and North, R.A. (1992) Opioids Excite Dopamine Neurons by Hyperpolarization of Local Interneurons. Journal of Neuroscience, 12, 483-488.

[10] Kreek, M.J., Levran, O., Reed, B., Schlussman, S.D., Zhou, Y. and Butelman, E.R. (2012) Opiate Addiction and Co- 
caine Addiction: Underlying Molecular Neurobiology and Genetics. J Clin Invest, 122, 3387-3393. http://dx.doi.org/10.1172/JCI60390

[11] Tegeder, I. and Geisslinger, G. (2004) Opioids as Modulators of Cell Death and Survival-Unraveling Mechanisms and Revealing New Indications. Pharmacological Reviews, 56, 351-369. http://dx.doi.org/10.1124/pr.56.3.2

[12] Salama, A. (2009) Drug-Induced Immune Hemolytic Anemia. Expert Opinion on Drug Safety, 8, 73-79. http://dx.doi.org/10.1517/14740330802577351

[13] Kronstadt, D. (1991) Complex Developmental Issues of Prenatal Drug Exposure. The Future of Children, 1, 36-49. http://dx.doi.org/10.2307/1602613

[14] Chasnoff, I.J., Burns, K.A., Burns, W.J. and Schnoll, S.H. (1985) Prenatal Drug Exposure: Effects on Neonatal and Infant Growth and Development. Neurobehavioral Toxicology and Teratology, 8, 357-362.

[15] Methadone and Pregnancy. http://www.methadoneandpregnancy.com/

[16] Broussard, C.S., Rasmussen, S.A., Reefhuis, J., Friedman, J.M., Jann, M.W., Riehle-Colarusso, T. and Honein, M.A. (2011) Maternal Treatment with Opioid Analgesics and Risk for Birth Defects. American Journal of Obstetrics and Gynecology, 204, 314.e1-314.e11. http://dx.doi.org/10.1016/j.ajog.2010.12.039

[17] Yazdy, M.M., Mitchell, A.A., Tinker, S.C., Parker, S.E. and Werler, M.M. (2013) Periconceptional Use of Opioids and the Risk of Neural Tube Defects. Obstetrics \& Gynecology, 122, 838-844. http://dx.doi.org/10.1097/AOG.0b013e3182a6643c

[18] Geber, W.F. and Schramm, L.C. (1975) Congenital Malformations of the Central Nervous System Produced by Narcotic Analgesics in the Hamster. American Journal of Obstetrics \& Gynecology, 123, 705-713.

[19] Katz, S., Ben-Hur, T., Ben-Shaanan, T.L. and Yanai, J. (2008) Reversal of Heroin Neurobehavioral Teratogenicity by Grafting of Neural Progenitors. Journal of Neurochemistry, 104, 38-49.

[20] Güntürkün, O. (2005) The Avian “Prefrontal Cortex” and Cognition. Current Opinion in Neurobiology, 15, 686-693. http://dx.doi.org/10.1016/j.conb.2005.10.003

[21] Stahler, A.C., Monahan, J.L., Dagher, J.M., Baker, J.D., Markopoulos, M.M., Iragena, D.B., NeJame, B.M., Slaughter, R., Felker, D., Burggraf, L.W., Isaac, L.A.C., Grossie, D., Gagnon, Z.E. and Pavel-Sizemore, I.E. (2013) Evaluating the Abnormal Ossification in Tibiotarsi of Developing Chick Embryos Exposed to $1.0 \mathrm{ppm}$ Doses of Platinum Group Metals by Spectroscopic Techniques. Bone, 53, 421-429. http://dx.doi.org/10.1016/j.bone.2012.12.051

[22] US Department of Health and Human Services (2008) Frequently Asked Questions about the Public Health Service Policy on Humane Care and Use of Laboratory Animals. http://www.nih.gov/grants/olaw/references/ilar93.htm

[23] Gagnon, Z.E., Isaac, L.A.C. and Newkirk, C. (2008) Neural Damage in Chick Embryo Brains Exposed to Platinum Group Metals. In: Collery, P., Maymarad, I., Theophanides, T., Khassanova, L. and Collery, T., Eds., Metal Ions in Biology and Medicine, Volume 10, John Libbey Eurotext, Paris, 82-87.

[24] Hamburger, V. and Hamilton, H.L. (1955) A Series of Normal Stages in the Development of the Chick Embryo. Journal of Morphology, 88, 49-92. http://dx.doi.org/10.1002/jmor.1050880104

[25] New, D.A.T. (1966) The Culture of Avian Embryos. Logos Press, London.

[26] Bellairs, R. and Osmond, M. (1998) The Atlas of Chick Development. Academic Press, New York.

[27] Hans, S.L. and Jeremy, R.J. (2001) Postnatal Mental and Motor Development of Infants Exposed in Utero to Opioid Drugs. Infant Mental Health Journal, 22, 300-315. http://dx.doi.org/10.1002/imhj.1003

[28] Pizarro, D., Habli, M., Grier, M., Bombrys, A., Sibai, B. and Livingston, J. (2011) Higher Maternal Doses of Methadone Does Not Increase Neonatal Abstinence Syndrome. Journal of Substance Abuse Treatment, 40, 295-298. http://dx.doi.org/10.1016/j.jsat.2010.11.007

[29] Schrott, L.M., Baumgart, M.I., Zhang, X. and Sparber, S.B. (2002) Prenatal Opiate Withdrawal Activates the Chick Embryo Hypothalamic-Pituitary-Adrenal Axis and Dilates Vitelline Blood Vessels via Serotonin2 Receptors. Journal of Pharmacology and Experimental Therapeutics, 303, 257-264. http://dx.doi.org/10.1124/jpet.102.037044

[30] Csillag, A., Bourne, R.C. and Stewart, M.G. (1990) Distribution of Mu, Delta, and Kappa Opioid Receptor Binding Sites in the Brain of the One-Day-Old Domestic Chick (Gallus domesticus): An in Vitro Quantitative Autoradiographic Study. The Journal of Comparative Neurology, 302, 543-551. http://dx.doi.org/10.1002/cne.903020310

[31] Campbell, T.W. (1995) Avian Hematology and Cytology. 2nd Edition, Iowa State University Press, Ames.

[32] Campbell, T.W. (1994) Hematology. In: Ritchie, B.R., Harrison, G.J. and Harrison, L.R., Eds., Avian Medicine: Principles and Application, Wingers Publishing, Lake Worth, 176-198.

[33] Hu, S., Sheng, W.S., Lokensgard, J.R. and Peterson, P.K. (2002) Morphine Induces Apoptosis of Human Microglia and Neurons. Neuropharmacology, 42, 829-836. http://dx.doi.org/10.1016/S0028-3908(02)00030-8

[34] Li, Y., Sun, X., Zhang, Y., Huang, J., Hanley, G., Ferslew, K.E., Peng, Y. and Yin, D. (2009) Morphine Promotes 
Apoptosis via TLR2, and This Is Negatively Regulated by Beta-Arrestin 2. Biochemical and Biophysical Research Communications, 378, 857-861. http://dx.doi.org/10.1016/j.bbrc.2008.12.001

[35] Li, Y., Li, H., Zhang, Y., Sun, X., Hanley, G.A., LeSage, G., Zhang, Y., Sun, S., Peng, Y. and Yin, D. (2010) Toll-Like Receptor 2 Is Required for Opioids-Induced Neuronal Apoptosis. Biochemical and Biophysical Research Communications, 391, 426-430. http://dx.doi.org/10.1016/j.bbrc.2009.11.074

[36] Loughlin, S.E., Kornblum, H.I., Massamiri, T. and Leslie, F.M. (1991) Transient Appearance of Beta-Endorphin Immunoreactive Cells within the Germinal Zone of Neonatal Rat Forebrain. International Journal of Developmental Neuroscience, 9, 493-500. http://dx.doi.org/10.1016/0736-5748(91)90035-K

[37] Bartolome, J.V., Bartolome, M.B., Daltner, L.A., Evans, C.J., Barchas, J.D., Kuhn, C.M. and Schanberg, S.M. (1986) Effects of Beta-Endorphin on Ornithine Decarboxylase in Tissues of Developing Rats: A Potential Role for This Endogenous Neuropeptide in the Modulation of Tissue Growth. Life Sciences, 38, 2355-2362. http://dx.doi.org/10.1016/0024-3205(86)90643-0

[38] Andersen, S.N. and Skullerud, K. (1999) Hypoxic/Ischaemic Brain Damage, Especially Pallidal Lesions, in Heroin Addicts. Forensic Science International, 102, 51-59. http://dx.doi.org/10.1016/S0379-0738(99)00040-7

[39] Friesen, C., Roscher, M., Hormann, I., Fichtner, I., Alt, A., Hilger, R.A., Debatin, K.M. and Miltner, E. (2013) Cell Death Sensitization of Leukemia Cells by Opioid Receptor Activation. Oncotarget, 4, 677-690. http://dx.doi.org/10.18632/oncotarget.952

[40] Newkirk, C.E., Gagnon Z.E. and Sizemore-Pavel, I.E. (2014) Comparative Study of Hematological Responses to Platinum Group Metals, Antimony and Silver Nanoparticles in Animal Models. Journal of Environmental Science and Health, Part A, 49, 269-280. http://dx.doi.org/10.1080/10934529.2014.846589

[41] McKenzie, S.B. and Williams, J.L. (2010) The Leukocyte. In: McKenzie, S.B. and Williams, J.L., Eds., Clinical Laboratory Hematology, Chapter 7, 2nd Edition, Prentice Hall, Upper Saddle River, 331-366. 